\title{
Features of Problem-Based Module Design When Developing Professional Competencies in Bachelor Students Majoring in Radio Engineering
}

\author{
Galina Ivanovna Smirnova ${ }^{1} \&$ Valery Georgievich Katashov ${ }^{2}$ \\ ${ }^{1}$ Volga State University of Technology, Yoshkar-Ola, Russia \\ ${ }^{2}$ Kazan Federal University, Kazan, Russia \\ Correspondence: Galina Ivanovna Smirnova, Volga State University of Technology, Yoshkar-Ola, 3 Pl. Lenina, \\ Republic of Mari El, 424000, Russian Federation. E-mail: SmirnovaGI@volgatech.net
}

Received: January 19, 2014

Accepted: February 22, 2015 Online Published: March 25, 2015

doi:10.5539/res.v7n5p17

URL: http://dx.doi.org/10.5539/res.v7n5p17

\begin{abstract}
The problem is vitally important today due to the fact that problem-modular training as an effective technology of engineering education should be integrated into the curriculum, however it is implemented in a few disciplines only. The paper is aimed at applying problem-based learning in modular and competence training of bachelor students majoring in engineering. This is meant to develop professional competences in bachelor students that would be adequate for the innovative economy thus putting emphasis on students' practical activity and evolving their engineering thinking. The design is particularly characterized by systematization of professional training challenges by standardization of production objectives and situations and offering proper solution using group learning methods. The contents of problem-based modules as applicable to bachelors' academic training is aligned with Federal and State Standards of Higher Professional Education in the Russian Federation in Radio Engineering as well as contents structuring by integrating a number of disciplines. The paper may represent interest for specialists involved in engineering training program design in accordance with the international European standards EUR-ACE aimed at achieving the following learning outcomes: engineering analysis, engineering design, research and practice.
\end{abstract}

Keywords: problem-based learning, modular-competence training, engineering education

\section{Introduction}

\subsection{Actuality of the Problem}

The transition to a multi-level system in professional training puts into the foreground the problem of professional competence development in to-be engineers. It has become significantly relevant when training students majoring in radio-engineering. After mastering key technical courses the students are able to demonstrate key competencies on the lowest level, the level of understanding (Biktagirova \& Valeeva, 2013, 2014, 2015; Gatiyatullin \& Nigmatov, 2014; Shaidullina et al., 2015; Ivanov et al., 2015). Only 2-3 per cent of students can demonstrate these competencies on the level of responsible awareness (Valeeva \& Valeeva. 2013; Valeeva et al., 2015; Masalimova \& Sabirova, 2014, 2015; Sibgatova et al., 2015; Shaidullina et al., 2014; Ganieva et al., 2014).

From the didactics perspective the leading prerequisite for competence and innovative thinking development is the integration of new technologies into the learning process based on problem-based approach. As for engineering training the integration of problem-based learning is considered in terms of certain courses, such as Physics (Larionov, 2008), Foreign Language, Mathematics (Stepanova, 2006; Nigmatov, 2015; Zaripova et al., 2014) and some others.

The problem is underdeveloped on the systematic interdisciplinary level, especially when it comes to the field-specific courses.

This results in the need for problem-based modular system development aimed at training bachelor students majoring in radio engineering and aligned with Federal State Educational Standards of Higher Professional Education. 
Therefore, our paper is aimed at indicating the possible systematization of the problem and methods for defining the contents of educational modules with training bachelor students majoring in technical disciplines.

\subsection{Explore the Importance of the Problem}

Engineering education is evolving towards international integration and accreditation, therefore, it should be aligned with international standard requirements for engineering programs accreditation (Why accreditation matters, 2011-2013), taking into consideration qualifications framework (QF) of higher professional education (ABET Vision and Mission, 2011). The priority one is EUR-ACE (EUR-ACE Framework Standards for the accreditation of engineering programmes, 2008), (A Framework for qualifications of the European Higher Education Area, 2005) and Graduate Attributes and Professional Competencies (Graduate Attributes and Professional Competencies, 2013). In accordance with the QF mentioned all the learning outcomes have been systematized and distributed within the following six key elements: knowledge and understanding, engineering analysis, engineering design, research, practice, personal skills. The achievement of these learning outcomes is possible on condition that there is interdisciplinary integration, when every element is a complete educational module containing a number of courses.

\subsection{Status of a Problem}

In accordance with the Federal State Educational Standards of Higher Professional Education and the requirements imposed by the radio engineering industry the following didactic principles of education should be taken into consideration when applying a modular and competence-based approach:

- The principle of scientific approach when structuring problem-based modules aimed at the development of professional competencies;

- The principle of visibility that presumes the use of technical equipment that would facilitate students' comprehensive understanding of all kinds of interconnected knowledge from various key and general subjects in every module;

- The principle of the system approach that means such a module structure under which training would embrace all the elements of knowledge necessary to carry out a certain type of work in a radio engineering field to its fullest extent and proper logics;

- The principle of responsibility under which the module designed can be mastered, its practical relevance is evident and it evokes students' interest and stirs their activity when mastering a particular competence;

Problem-based education allows to implement the principles defined in the most effective way.

Depending on these principles the efficiency of these methods are used by a number of international educationalists although with different deliverables (Pokholkov \& Agranovich, 2012; Lopatina et al., 2015; Ivanenko et al., 2015; Sakhieva et al., 2015; Khairullina et al., 2015).

Below there are the most evident results:

- Students become more interested and engaged in independent work;

- Students take less time to be aware of the importance and necessity of learning theory, laws and rules that would guarantee the working capacity of a competent specialist;

- Students understand the algorithm of dealing with non-routine professional situations;

- Students develop intrinsic interest to learning courses as well as become better professionally motivated (Lisitzina et al., 2014);

- Thus, students are actively trained to join the real industry (Nurtazin, Bazarbaeva, Esimsiitova, \& Ermekbaeva, 2013).

The analysis of the research carried out in the field of introducing problem-based learning in training bachelor students majoring in radio engineering proved that the major requirement for innovative programs design is the scientific and systems approach along with wide coverage of interconnected subject areas taking into consideration the integration of knowledge and skills that act as a basis for certain competencies development.

The educational technologies proved to be well demanded by students. These educational technologies started developing mainly for professional fields where it was impossible or dangerous to create real-life industrial situations. These include, for example, jobs in medicine when treating one organ depends in the other ones thus requires establishing problem-based modules that would combine related courses, for example, Pathological Anatomy, Pathological Physiology, etc. (Fedorina, 2013) 
Radio engineering refers to one of the fields where it is hard to simulate many real working situations, therefore the major problem of introducing problem-based learning is the necessity for continuous content update due to the rapid changes occurring in radio engineering technologies. In order to meet this requirement the modules should be flexible and easily adapted to the changing situations. Therefore the problem modules for bachelors majoring in radio engineering should also be systematic and flexible.

\section{Methodological Framework}

Deeper research into the problem of enhancement of bachelor students' professional competencies proved that a certain number of evident yet difficult to implement conditions are to be carried out.

Training bachelors majoring in radio engineering that would meet the innovative industry requirements faces at least two obstacles: on the one hand, the didactic weakness of bachelor students' educational activity, on the other, we see misalignment between higher professional school and industry.

This understanding made it possible to put forward the following didactic and educational conditions:

By the first pedagogical condition we mean here active development of key professional competencies, which occur while carrying out specific projects. The projects become more sophisticated as the students progress in their project activity. First of all the project was split into modules, each with a problem situation. In the didactics this approach is knows as problem modular design of learning. Despite its all advantages there is a very significant disadvantage. Problem-based modular projects are being developed without taking into consideration the real level of students' basic theoretical knowledge, the level of their radio engineering thinking, their real working experience. In other words it is assumed that students are ready for problem-based learning and no additional training is needed. Thus, we can define the first necessary condition, i.e. it is necessity to take into consideration the basic didactic requirements applicable to the process of key professional competencies development when designing the problem modules. Some of these requirements are as follows:

- Problem module design aimed at formation or development of a certain competence is carried out in a very logical manner: actualization of basic radio engineering knowledge, application of this knowledge in a typical radio engineering situation, practical solution of a non-typical problem from the real industry;

- Problem module design is supplemented with didactic educational resources, adequate for the contemporary radio engineering industry or its support system (visual aids, laboratory and user equipment can be found in real life industry, there are computer-aided simulators);

- Problem module design should be based on interdisciplinary relations. It would be an ideally appropriate situation when teachers of interconnected subjects at the same time demonstrate professional competencies and design their modules in the logical unity;

- The Federal State Educational Standards of Higher Professional Education are aimed at the development of professional competencies in terms of professional activity simulation. Therefore, in order to develop key competencies it is highly recommended to include simulating educational technologies into the learning process. In practice there is often a very primitive imitation of industrial conditions transferred to the learning environment which doesn't develop the required competencies or, even worse, blocks or develops the wrong ones.

By the second pedagogical condition we understand that even within didactically verified learning process the development of professional competencies requires high extrinsic motivation which defines the specialist's social status. It is the necessary requirement that radio engineering specialists should be well demanded in industry or support service offered a decent salary.

Implementation of the conditions mentioned above should make the process of professional competencies development more accomplishable and effective. These conditions are to be met only under the systems approach to professional education modernization.

\section{Results}

The process of problem module design includes the following aspects:

- Identifying modules;

- Setting module goals;

- Selecting contents for modules;

- Educational technologies applicable for the modules. 
The solution of module identification problem is closely connected with the goals set for each module. By means of orienting learning on innovative production it is necessary to emphasize that creating research and industrial problems when training bachelors in radio engineering should be interconnected with professional competencies aimed at solution of certain professional tasks.

Analysis of Federal State Educational Standards of Higher Professional Education demonstrated the extensive variety of such tasks in the framework of all kinds of bachelor students' future professional activity. Bringing the modules in compliance with these tasks is sure to lead to bulky and unmanageable education system. Therefore it is necessary to systematize and group the professional tasks in order to minimize their number and make them achievable. Thus the solution of this problem is possible once the tasks are unified on the criterion of common features of solution methods.

For example, the professional tasks that involve collecting research and technical information are present in two types of activities for the following unified tasks:

\section{Design and engineering task:}

- Collecting and analyzing the source data necessary for calculation and design of component parts, nodes and units of radio engineering systems;

Research task:

- Analysis of research data provided by home and international scholars devoted to the field of studies;

- Preparing reviews and reports based on the research results;

- Protection of intellectual property and research results and developments (Federal State Educational Standard of Higher Professional Education in Radio Engineering (Bachelor's Program), 2009).

All these tasks are subject to one solution method, therefore can be grouped into one generalized professional task: collecting research and technical information, national and international experience including patents and its analysis for further research, calculation and design of technical appliances.

In the process of learning every module is aimed at the formation or development of certain professional competencies aimed at the most effective solution of a generalized professional task. Since the Federal Standard contains a large number of professional competencies, they also need to be systematized for every module (Smirnova, 2014). As a result the module described is aimed at the development of the following professional competencies: ability to collect, process, analyze and systematize research and technical information on the subject and design under study which at the same time characterizes the development of innovative radio engineering thinking to a large extend. Developing this kind of thinking implies orientation of every module on a certain problem solution. For this reason the information should be selected and systematized as applicable to contemporary engineering devices competitive in industry.

The hardest challenge when implementing problem based learning is setting a didactically well-grounded problem. Taking into consideration a number of recommendations (Makhmutov, 1972) the problem to the above mentioned module can be formulated as follows: How is it possible to detect the radar targets that use stealth technologies? In order to solve this problem it is necessary to review research and technical information in the shortest possible time and with a high degree of accuracy to find analogues and prototypes of principles and algorithms of stealth target detection in national and international patented literature.

In terms of other core industries the problem might be defined in a different way; however the solution methods will be the same.

Thus students develop the necessary competencies.

Professional competencies are developed only in doing; therefore the methods of problem solution within the generalized professional tasks should be the basis of module contents.

Problem solution methods define the module contents which can be structured by integrating a number of disciplines.

In terms of the example under study from Federal State Educational Standard of Higher Professional Education these can be either compulsory courses, such as Information Technologies, Foreign Language, Digital Devices and Microprocessors or optional courses, such as Patenting and Intellectual Property Protection, Marketing in the Field. The methods of information collection is developed within the courses of Technologies, Foreign Language, Patenting and Intellectual Property Protection. The subject matter of the problem is disclosed within the professional courses like Digital Devices and Microprocessors, etc. 
As a result we get a logical and content-based intercourse integration and professional competencies training when carrying out the projects of the professional cycle.

In order to permanently reinforce the developed skills and competencies it is necessary to repeat the basic methods of work a number of times. It is suggested to use the technology of group project work and computer simulators.

Group design is applicable on the module and course levels. On the course level it is necessary to use computer simulators created for example on the LabView platform and meant to master the algorithms of generalized professional task solutions within certain courses. Carrying out the projects within these courses involves design, simulation of the typical elements of technical equipment and measurements of the basic characteristics and their interrelations.

When mastering the module we would recommend to create mixed groups. The group should be supervised by a student studying the core subject that completes the course of studies, the rest of the group should still be in the process of studying prerequisites of this core subject. The project is aimed at developing the device with the principles of work studied within the core subject. For example, Radio Engineering Systems is the closing course in Radio Engineering Bachelor's programme. The basic technical device to be developed by a student is the radar set that contains the following basic components: pulse synthesizer, transmission unit, radio-frequency channel, target, receiving unit, digital signal processing unit. On the level of certain courses there will be some projects aimed at producing separate components of the radar system. Here we deal with such prerequisite courses, such as Basics of Transmission Units Design, Basics of Receiving Units Design, Electrical Dynamics and Wave Propagation, Digital Devices and Micro Processors, Digital Signal Processing, Radio Countermeasures and Interference Immunity, etc.

\section{Discussions}

It is the peculiar feature of problem modular-based design that they do not represent a part of the course as a topic or a section as it is typical for traditional education (Smirnova, 2014). Every module integrates a number of courses aimed at the development of professional competencies that allow to improve the quality of learning by thorough system approach.

The criterion of intercourse integration significantly differs from the traditional criteria.

It is not based on the morphological analysis of the learning material as it is practiced in traditional engineering (Karpov, 1992) or medical (Fedorina, 2013) learning, but represented in the form of unified professional tasks. It allows to intensify the process of competence mastering and better prepares graduates for their professional activity.

Unification of professional tasks allowed to define generalized professional tasks and obtain the optimum module number that are possible to be covered completely within the Bachelor's program.

The contents of study modules include certain course units represented as algorithms when dealing with generalized professional tasks. In this case the number of competencies mastered in each course equals the number of courses.

In order to develop creative and innovative thinking and implementing the principles of modular-based learning it is suggested to begin every module with a problem definition which should be applicable to modern technical devices, competitive in the industry. This approach allows to significantly stir the interest to learning and therefore acts as a driving force to the development of mental capacity and engineering thinking.

Since the problem issues are successfully solved in group work, in order to master competencies it is recommended to use these kinds of learning methods supplemented by virtual environment tools and simulators.

Group work on a project is sure to enhance intrinsic motivation in students involved which is very important for the learning activity stimulation and students' independent work.

One of the advantages of this technology is the individual accountability of every group member and a small group: the success of a mini project will guarantee the success of a global project.

Team-building methods meant to provide psychological compatibility of all group members and well-developed methodological recommendations that would contain well-grounded recommended sequences of activities represent the necessary condition of module-based group educational approach which would stimulate the success situations in students.

Use of simulators allows to create a "big picture" of the work carried out, i.e. to concentrate on the systematic 
ways of problem solution, see the project results, correct and amend the previously made decisions rather than concentrate on some minor calculations. On the other hand, this approach allows to avoid copyright problem when the ready calculations are downloaded from the internet but stir original thoroughly considered solutions.

\section{Conclusion}

Thus, the quality of higher professional training and competence development by doing and innovative thinking, so much required by the innovative economics can be obtained in competence-based modular program design for bachelor students majoring in engineering with the use of problem-based education.

As our research proved, the approach applied makes it possible to systematize the industrial tasks and situations, collect the problem industrial cases and classify those into modules that are content adaptable within the Bachelor's program.

In this case the learning modules based on generalized professional tasks are sure to embrace all the professional tasks that reflect the future activity of radio engineering specialists. Every module should be oriented on key competence mastering and organized as a problem the solution of which involves intercourse integration. Group design and computer simulators improve the efficiency of problem solution.

Thus, such approach is sure to create conditions for problem-based learning of the whole Bachelors' study program using intercourse integration rather than on the level of separate courses.

\section{Recommendations}

The research results are considered from the point of view of professional competencies that are developed within professional disciplines.

The results obtained correspond to the contemporary trends in the field of higher professional training in modular-based and intercourse integration. In accordance with the accreditation criteria developed by European engineering programs, the results obtained can be referred to the following learning outcomes groups: engineering analysis, engineering design, research and practice (EUR-ACE Framework Standards for the accreditation of engineering programmes, 2008), (A Framework for qualifications of the European Higher Education Area, 2005), (Graduate Attributes and Professional Competencies, 2013). These can be used when developing the methodology of engineering study programs design based on alignment of EUR-ACE standards and Russian Federal Educational Standards.

\section{Acknowledgments}

The work was supported by the Ministry of Education and Science of the Russian Federation Research Work No 2755 by order No 2015/82.

\section{References}

ABET Vision and Mission. (2011). Baltimore. In ABET: The office site. Retrieved from http://www.abet.org/vision-mission

Biktagirova, G. F., \& Valeeva, R. A. (2015). Formation of University Students' Readiness for Parenthood. Review of European Studies, 7(4), 93-97. http://dx.doi.org/10.5539/res.v7n4p93

Biktagirova, G. F., \& Valeeva, R. A. (2013). Technological approach to the reflection development of future engineers. In 2013 International Conference on Interactive Collaborative Learning (p. 427). http://dx.doi.org/10.1109/ICL.2013.6644615

Biktagirova, G. F., \& Valeeva, R. A. (2014). Development of the teachers' pedagogical reflection. Life Science Journal, 11(9), 60-63.

ECDEAST: Engineering curriculum design aligned with the EQF and EUR-ACE Standards. (2010-2013). Website Tomsk. TPU. Retrieved from http://www.ecdeast.tpu.ru/en

EUR-ACE Framework Standards for the accreditation of engineering programmes (2008). ENAEE (cop. ENAEE, 2012): The office. http://www.enaee.eu/wp-content/uploads/2012/01 /EUR-ACE_Framework-Standards_2008-11-0511.pdf

Federal State Educational Standard of Higher Professional Education in Radio Engineering (Bachelor's program). (2009). Moscow. Retrieved from http://fgosvo.ru/uploadfiles/fgos/20/20111115154734.pdf

Fedorina, T. A. (2013). On our experience of module approach to the curriculum organization at the Department of General and Clinical Pathology. Vestnik of Saint Petersburg University, Series 11 Medicine, 2, 211-213.

Ganieva, Y. N., Azitova, G. S., Chernova, Y. A., Yakovleva, I. G., Shaidullina, A. R., \& Sadovaya, V. V. (2014). 
Model of high school students professional education. Life Science Journal 11(8), 504.

Gatiyatullin, M. K., \& Nigmatov Z. G. (2014). Formation of entrepreneurship culture with technical university students. Middle-East Journal of Scientific Research, 19(4), 544-560.

Graduate Attributes and Professional Competencies. (2013). Int. Eng. Alliance. Version 3. The International Engineering Alliance $\quad$ website. $\quad$ Retrieved from http://www.ieagreements.org/IEA-Grad-Attr-Prof-Competencies.pdf

Ivanenko, N. A., Akhmetov, L. G., Lavrentiev, S. Y., Kartashova, E. P., Lezhnina, L. V., Tzaregorodtzeva, K. A., \& Khairullina, E. R. (2015). Features of Modeling the Formation of Teaching Staff Competitiveness. Review of European Studies, 7(3), 37-42. http://dx.doi.org/10.5539/res.v7n3p37

Ivanov, V. G., Shaidullina, A. R., Drovnikov, A. S., Yakovlev, S. A., \& Masalimova, A. R. (2015). Regional Experience of Students' Innovative and Entrepreneurial Competence Forming. Asian Social Science, 11(1), 35-40.

Karpov, V. V., Kathanov, M. N., \& Sviridov, N. G. (1992). Methodology of teachers' training at the FPKP course within multilevel system of university education (p. 107). Moscow.

Khairullina, E. R., Valeyev, A. S., Valeyeva, G. K., Valeyeva, N. S., Leifa, A. V., Burdukovskaya, E. A., \& Shaidullina, A. R. (2015). Features of the Programs Applied Bachelor Degree in Secondary and Higher Vocational Education. Asian Social Science, 11(3), 213-217.

Larionov, V. V. (2008). Problem-based Physics learning teaching and learning at technical universities (p. 270). Moscow. http:/www.dissercat.com/content/problemno-orientirovannoe-obuchenie-fizike-studentov-vtekhnicheskikh-universitetakh

Lisitzina, T. B., Pavlova, A. V., Khanmurzina, R. R., Vlasova, V. N., Chitalin, N. A., Maksimov, I. N., \& Zakirova, V. G. (2014). Features of the Professional and Motivating Training Content Design for Students Majoring in “Tourism”. Asian Social Science, 11(1), 148-152. http://dx.doi.org/10.5539/ass.v11n1p148

Lopatina, O. V., Fassakhova, G. R., Akhmetova, L. A., Gatin, R. G., Yarullina, A. S., Nikishina, S. R., \& Khairullina, E. R. (2015). The Technology of Forming the Students' Research Competence in the Process of Learning a Foreign Language. Asian Social Science, 11(3), 152-157.

Makhmutov, M. I. (1972). Theory and practice of problem-based learning (p. 365). Kazan.

Masalimova, A. R., \& Sabirova, L. L. (2014). Multi-dimensional classificationof types and forms of corporate education. American Journal of Applied Sciences, 11, 1054-1058. http://dx.doi.org/10.3844/ajassp.2014.1054.1058

Masalimova, A. R., \& Sabirova, L. L. (2015). Mentors and Trainees Professional Interaction Features at the Modern Enterprises in Russia. Review of European Studies, 7(4), $20-26$. http://dx.doi.org/10.5539/res.v7n4p20

Nigmatov, Z. G. (2015). Methodic techniques of solving technical problems developing technical students' thinking. Review of European Studies, 7(1), 171-175.

Nurtazin, S. T., Bazarbaeva, Z. M., Esimsiitova, Z. B., \& Ermekbaeva, D. C. (2013). An innovative method of "problem-based learning" (Problem-Based Learning -PBL). Success of modern natural science, 5, 112-114.

Pokholkov, Y. P., \& Agranovich, B. L. (2012). National doctrine design principles in Russian engineering education within the new-type of industrialization: Problems, objectives, challenges. Engineering Education, 9, 5-11.

Sakhieva, R. G., Ibatullin, R. R., Biktemirova, M. K., Valeyeva, G. K., Pchelina, O. V., Valeyeva, N. Sh., Minsabirova, V. N., \& Khairullina, E. R. (2015). The Essential, Objective and Functional Characteristics of the Students' Academic Mobility in Higher Education. Review of European Studies, 7(3), 335-340. http://dx.doi.org/10.5539/res.v7n3p335

Shaidullina, A. R., Fassakhova, G. R., Valeyeva, G. K., Khasanova, G. B., Komelina, V. A., \& Ivanova, T. L. (2015). A Comparative Research on Levels of Students' Formation Skills of Their Career Advancement Portfolio in Secondary and Higher Education Systems. Asian Social Science, 11(1), 375-379.

Shaidullina, A. R., Masalimova, A. R., Vlasova, V. K., Lisitzina, T. V., Korzhanova, A. A., \& Tzekhanovich, O. M. (2014). Education, science and Manufacture Integration Models features in Continuous Professional Education System. Life Science Journal, 11(8s), 478-485. 
Sibgatova, K. I., Mirzagalyamova, Z. N., Pupysheva, E. L., Mirzanagimova, F. I., Shkinderova, I. N., Nuriyeva, E. N., Masalimova, A. R., \& Schepkina, N. K. (2015). The Educational Institution Teachers and Professional Community Representatives' Readiness Formation for the Joint Pupils' Career Guidance Implementation. Review of European Studies, 7(1), 74-79.

Smirnova, G. I. (2014). Modular program design for competence training of engineering students. Higher Education Today, 1, 44-49.

Stepanova, O. M., Kozlova, N. V., Kryuchkov, Y. Y., \& Soloviev, M. A. (2006). Introduction of problem-based technologies into the educational process in technical universities. Bulletin of the Tomsk Polytechnic University, 1, 242-246.

Valeeva, L. A., \& Valeeva, R. A. (2013). Development of future engineers' critical thinking in foreign language teaching (p. 438). 2013 International Conference on Interactive Collaborative Learning. ICL.

Valeeva, R. A., Koroleva, N. E., \& Sakhapova, F. K. (2015). Civic education of the technical university students in foreign language classes. Review of European Studies, 7(1), 176.

Why accreditation matters. Ibid. (2011-2013). ABET website. Retrieved from http://www.abet.org/why-accreditation-matters

Zaripova, I. M., Shaidullina, A. R., Upshinskaya, A. Y., Sayfutdinova, G. B., \& Drovnikov, A. S. (2014). Modeling of Petroleum Engineers Design-Technological Competence Forming in Physical-Mathematical Disciplines Studying Process. American Journal of Applied Sciences, 11(7), 1049-1053. http://dx.doi.org/10.3844/ajassp.2014.1049.1053

\section{Copyrights}

Copyright for this article is retained by the author(s), with first publication rights granted to the journal. This is an open-access article distributed under the terms and conditions of the Creative Commons Attribution license (http://creativecommons.org/licenses/by/3.0/). 